\title{
A Survey Report on: Become Prudent with Big Data - Technological sophistication in India
}

\author{
Sujata A. Pardeshi ${ }^{1}$, Pooja K. Akulwar ${ }^{2}$ \\ ${ }^{1}$ Assistant Professor, Department of Computer Science \& Engineering, Sanjay Ghodawat Group of \\ Institution's, Atigre, Maharashtra, India \\ ${ }^{2}$ Assistant Professor, Department of Computer Science \& Engineering, Sanjay Ghodawat Group of \\ Institution's, Atigre, Maharashtra, India
}

\begin{abstract}
In the world of globalization at 360 degree, a heavy digitalized rainy season has raised \& the rain drops of digital data is falling from the digitalized sky through lots of clouds of E-Commerce, MobileCommerce, Social Media, Internet things, Digital devices like Smart phones, Sensors, etc and the data streams have been escalating at the eye moment continuously without halt. Such a digitalized torrent of data stream is accommodating by a huge and very big ocean of the technological advancement of Big Data. Recently it has been seen that this big ocean of large data set mitigates and offers a big number of opportunities both for the existing and upcoming players to become big on the competitive track and also have a great impact on India and Indian Economy. According to NASSCOM \& CRISL, in India the Big Data Industry will grow from $\$ 200$ million in 2012 to an estimated \$1 billion in 2015 at a Calculated Annual Growth Rate of more than 83 percent and IDC states that, the market for big data moves around India \& will soon reach \$16.1 billion in 2014, growing 6 times faster than the overall IT market. Therefore to dive on the growing economical waves, it is important for Entrepreneur's and Organizers to become prudent in driving the technological sophistication ship in the journey of Big Data Ocean. The proposed study will be experienced about prudence in getting what is Big Data, how it was evolved, and what it involved in it?
\end{abstract}

Keywords: Big Data, Economy, Infrastructure, Investment, Technological Advancement

\section{Introduction}

The Big Data is characterized as massive volumes of data set having varieties of data with higher velocity that includes structured, unstructured and semi structured digitalized data generated through Internet means. The Big Data emerged before seventy years ago, which leaded to "Information Explosion" that described growth rate in volume of data. The following milestones in the history of sizing of data volumes that boost the evolution of the idea of "Big Data" [1] are:

- In 1994 Fremont Rider, Wesleyan University Librarian published,'The Scholar and the Future of the Research Library". He estimated that American university libraries were doubling in size every sixteen years and with respect to this growing rate he speculated that in 2024library will have "approximately 200000000 volumes, which will occupy over 6000 miles of shelves" and hence it is difficult to distribute across the study population and vice versa.

- In 1961 Derek Price, published "Science since Babylon" which shows growth of scientific knowledge through the scientific journals and papers and this growth doubles every fifteen years and increase by a factor of ten during every half century.

- In November 1967, B. A. Marron and P. D. D. deMaine published, "Automatic Data Compression" in the ACM communications, stating that "The Information Explosion noted recent years makes it essential that storage requirement be kept to a minimum corresponding to data population."

- In 1975, the Ministry of Posts and Telecommunications in Japan tracked volume of information that introduced "amount of words" as unifying unit of measurement and found that information supply is increasing tremendously than information consumption.

- In 1978, reports found that "Demand for information provided by mass media has become stagnant and demand for information provided by telecommunication media has drastically increased.

- In April 1980, at the fourth IEEE Symposium on Mass Storage Systems, I.A. Tjomsland described "large amount of data are being retained as users have no way of identifying obsolete data".

- In August 1983, Ithiel de Sola Pool published "tracking the flow of Information" which concludes that" Words made available to Americans through media grew at a rate of $8.9 \%$ per year. Much of the growth in the flow of information was due to the growth in broadcasting and later changed due to point to point media"

- In 1996, according to R.J.T. Morris "digital storage becomes more cost-effective for storing data than paper". 
- In October 1997, Michael Cox \& David Ellsworth published "Application-controlled demand paging for out-of-core visualization" in IEEE 8th conference and stated that "Visualization provides interesting challenge for computer systems where data sets are large, taxing capabilities of main memory, local disk and remote disk".

- In October 2000, Peter Lyman and Hal R. Varian published "How Much Information?" and their study found that "the world produced about 1.5 exabytes of unique information or about 250 megabytes for every man, woman and child on earth. Vast amount of unique information is created and stored by individual".

- Francis X. Diebold in November 2000 presented a paper titled, "Big Data Dynamic Factor Models for Macroeconomic Measurement and Forecasting" which stated much good Science has been forced to confront and has been benefited from "Big Data " phenomenon.

- Doug Laney in February 2001 published a note on"3D Data management: Controlling Data Volume, Velocity and Variety".

- Tim O'Reilly in September 2005 published "What is Web 2.0" and stated that "data is next generation Intel inside. Database management is a core competency of web 2.0 companies which need to be considered as' infoware' rather than merely software".

- Cisco in June 2008 released the "Cisco Visual Networking index-Forecast and methodology 2007-2012" and predicted that" IP traffic will be doubled every two years through 2012 and that will be reach half a zettabyte in 2012".

- Kenneth Cukier in February 2010, published a report on" Data, data everywhere. " and described that the world contains an unimaginably vast amount of digital information. The effect is being felt everywhere, from business to science, from governments to the arts and hence a new term arrived as "Big Data".

- Martin Hilbert \& Priscila Lopez published "The World's technological Capacity to Store, Communicate and Compute Information". They estimated that in 1986, $99.2 \%$ of storage capacity was analog, but in 2007, $94 \%$ of storage capacity was digital.

- In May 2011, Experts from the Mckinsey Global Institute published "Big Data: the next Frontier for innovation, competition and productivity".

The rest of this paper is organized as follows: In Section 2, we introduce the background study of investment on Big Data in India. In Section 3, the Big Data and its technological world sows the way in use of Big Data advancement. The section 4 makes the study on the current scenario of Big Data Market in India with the views of Industrialist and focus on the emerging trends in India. The Section 5 describes how Indian industries diving into Big Data ocean and what prudency is required to dive around it. The 6 and 7 specify the future scope and conclusion of the proposed study.

\section{Related work}

Big Data Infrastructure's offerings are based on the Map-Reduce and Hadoop technology and do not consider much of the analytical usage. Currently it has been supposed that with the Big Data it is not possible to integrate the historical data with new variety of generated data and solution to this is proposed by Tekiner, Firat ; Keane, John A.[2].

Wielki, J. [3], has studied that the analysis of the Big Data phenomenon, which describes growing role of data and information and their rapid increase in the new socio-economical reality.

Jay Lee, Edzel Lapira, Behrad Bagheri, Hung-an Kao[4] has stated that the globalization of the world's economies is a major challenge to the industries and needs to look forward towards the predictive manufacturing. To become more competitive, organizers needs to use advanced analytical tools and technique and hence giving rise to Big Data Environment.

\section{Background of Big Data in India}

In India, Big Data comes naturally as it occupied variety of culture, demography, religions, languages, etc and according to this there are variations and growth in business verticals and has its own business problems which need to be addressed for better growth. The technological advancement present in US and UK cannot be suited in India. But in the current scenario of India, the picture is changed dramatically where the young, dynamic entrepreneurs and organizations are looking forward towards the utilization of digital world and Internet things to capture their patron who increases per day and results into generation of voluminous digital data. The International Data Corporation [IDC] predicts that digital data will grow from 2.8 trillion gigabytes in 2012 to 40 trillion gigabytes and 50 billion devices will be connected to networks and the Internet by 2020 [5].Though this unprecedented volume of information may seem overwhelming, it offers unparalleled opportunities for companies willing to invest the time and money to analyze and utilize the data available. In India, entrepreneurs are looking to start with Big Data in terms of building pure technological infrastructure and analytical software to manage, analyze and acquire huge amount of data to get the required result that changes with respect to the dependent patron behaviour. But in controversy about the Indian business structure, enough data not is generated 
through the digital world and Internet things like US, Europe countries since patron population of these countries have been doing everything on the Internet. Currently, India accounts for 2.5 per cent of the global Big Data market of $\$ 8$ billion and is expected to grow to $\$ 1$ billion by 2015. National Association of Software and Services Companies [NASSCOM], in association with Credit Rating Information and Services Limited [CRISIL][6] Global Research \& Analytics states that, the business of handling Big Data in India is still small at \$200 million, but will grow fivefold to $\$ 1$ billion by 2015 at a Calculated Annual Growth Rate of more than 83 percent. Of this, 82.9\% Big Data Services, followed by analytics and will be growing with $17.1 \%$. IDC states that, the market for Big Data moves around India \& will soon reach $\$ 16.1$ billion in 2014, growing 6 times faster than the overall IT market. According to Tata Consultancy Services [TCS], the average amount Indian companies spent approximately \$ 9.5 million (Rs 52 crore) by 2013. Data Set is growing in the Indian Enterprise in 2013 and according to State of the Indian CIO Survey, 40 percent of Indian IT leaders plan to implement Big Data analytics over the course of this year -while $16 \%$ of them are already in the process of implementing it. Therefore the potential for Big Data market is growing greatest and offers the lift for the players of Indian economy.

\section{Big Data and Technological World}

Hadoop [7], formally called Apache Hadoop, is an Apache Software Foundation platform for scalable, distributed computing and often associated with the Big Data. Essentially it is an open source implementation of core Google technologies and concrete technology behind Big Data. It can provide fast and reliable analysis of both structured data and unstructured data. It has capabilities to handle large data sets and enables Big Data projects by providing an economic way to store and process masses of raw data. The most of companies have experienced the power of it in the initial stage to capture raw business data, demographics and data exhaust flowing from the Websites and Social Media and move towards the usages of data big data analytical tools to establish the mechanism to drive a more effective business.

MapReduce [8] is data processing algorithm used by Hadoop that performs the exhaustive analysis quickly by using parallel programming implementation, involves distributing a task across multiple nodes running a "map" function.

Hadoop Distributed File System - HDFS is a fault tolerant storage system that can store huge amounts of information, and survive storage failure without losing data. Without Higher level toolkits of Hadoop like Mahout, HBase, Hive, Pig, Mahout, Zookeeper and Sqoop, fully leveraging power of Big Data will only be possible in the largest enterprisers that have budget to make large amount of investment and motivate the small and middle scale organizers to make use of Hadoop to harness with Big Data.

Limitations:

- Hadoop is architected to accommodate and compute very large files. It does not perform well for small files that are stored in the distributed file system and has no economy of scale. Therefore, it is not a good way to organize and analyze large number of smaller files.

- The data warehouses are great at handling structured data, but there's a high cost for the hardware to scale out as volumes. In 2004, Wall Mart claimed that to have the largest data warehouse in industries with 500 terabyte of storage. In 2009, eBay storage amounted to 8 petabytes. Two years later, the Yahoo Warehouse totaled 170 petabytes of data storage. And due to rise in digitization, enterprises from various verticals have been generating voluminous digital data and there is need of capturing trillions of bytes of information. A key enabler for Big Data is the low-cost scalability of Hadoop. A petabytes Hadoop cluster will require between 125 and 250 nodes which costs $\$ 1$ million. The cost of a supported Hadoop distribution will have similar annual costs $\$ 4,000$ per node, which is a small fraction of an enterprise data warehouse and is up to $\$ 10-\$ 100$ s of millions.

\subsection{Views of Industrialists for Big Data}

\section{Big Data Market Scenario In India}

The followings are the views of Industrialists for Big Data and these are:

- Infosys Technologies Ltd [9] - "Our strategy is to tap the Big Data Space in two ways - mass scale enablement of our talent pool in Big Data and related technologies and churning out more IP", says Rajeev Nayar, Associate Vice President \& Head, Big Data Practice, Infosys

- Wipro Technologies Ltd [10] - "We at Wipro believe that Big Data needs to be approached from a business perspective, and not from a technology perspective", says KR Sanjiv, Global Head \& Senior VP, Analytics \& Information Management business unit.

- HCL Technologies [11] - Naresh Nagarajan, Senior VP, Enterprise Transformation Services, HCL Technologies says that the strategy of "Consulting Down' helps in handholding the customer on identified business service lines where it has invested in creating solutions and frameworks related to Big Data for different industry verticals such as healthcare and financial services. 
- Happiest Minds Technologies [12] - Venkatesh Subramanian, VP for Business Intelligence, Big Data \& Analytics Practice at Happiest Minds states that, "There are more than half a dozen projects and project discussions in progress".

- General Electric [GE][13] India, Amarjeet Singh, CIO, says that, "We started our Big Data journey in a huge way in 2011. Trends such as how we are doing in our software business came out of Big Data. By Q2 of 2012, we started seeing results and based on these results we will be investing more in the future,"

- Kokilaben Dhirubai Ambani Hospital, Rajesh Batra, VP, - "It's a reality. Not only is patient data growing, our requirements for creating vast storage space for medical records is also growing by the day. Since the deployment of a common hospital management system last year, organizational data has run into petabytes," and according to him Big Data is being seen as a game-changing asset.

- Philips India[14], Sreeji Gopinathan, Senior Director-IT - "Conventional data warehousing solutions area not going to be sufficient to analyze large data sets. We need solutions to implement parallel processing that provides relevant data in a time, to the right business people, in order to drive decisions \& will influence business parameters and performance,". According to him, "If we look at the way that functions like marketing, R\&D, sales, etcetera are run, it's changing. Concepts like Social Listening, Crowd-Sourcing, Mobility will generate huge amounts of data, much more than we have been handling so far,"

\subsection{The Emerging Trends in India and Big Data}

5.2.1. Many North American companies have taken initiatives on Big Data and investing approximately about $\$ 10$ million and improved their business decision making process. North America will continue to be the leading market for Big Data services and products for the foreseeable future. Companies in India are primarily invested in services and project implementation for global clients and not very much invested in internal Big Data initiatives. Growth of Indian companies depends on North America \& Europe, since they are already engaged with most of the clients across such countries. And these countries are walking towards to escalate the power of Big Data. Growing trends indicate that US, India, UK and Mexican companies are likely to invest in Big Data initiatives in the coming years. Figure 1 focus on \% of Big Data Initiatives made by companies across the world according to TCS Global Trend Study.

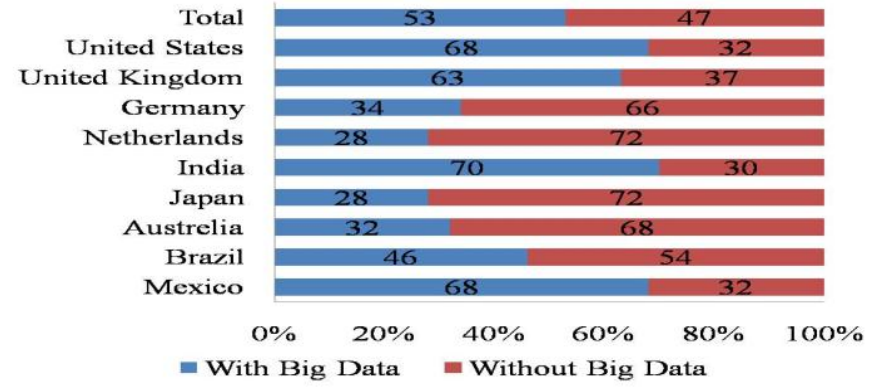

Fig.1 Percentage of Companies by Country with Big Data Initiatives in 2012

5.2.2. The opportunity offered by Big Data already grabbed by different types of business in India and it gives holistic view about Big Data technological advancements. The figure 2 shows the recent study conducted by EMC [15], [16] among Indian companies revealed about the types of business and their percentage of investment with Big Data. A new survey by Informatica Corporation revealed that 72 percent of Indian organizations are now considering, planning or running 'Big Data' projects, with organizations viewing the trend as an opportunity rather than an IT challenge by a greater than two-to-one

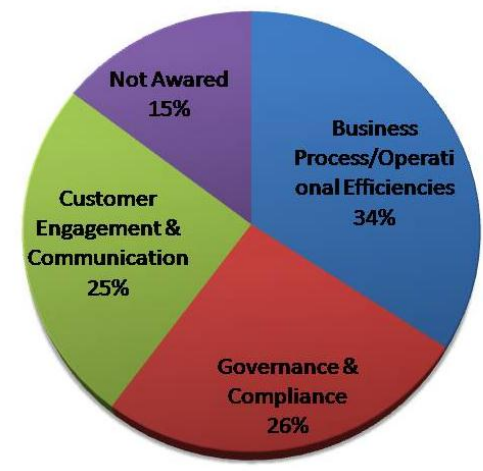

Fig.2 The Percentage of Investment Factor with Big Data 
5.2.3. A report study of SAP Business Trends shows that in India the Big Data is giving rise to markedly improved decision making and is having a significant impact on companies competitive differentiation and ability to turn away risk, the Figure 3 shows the percentage of respondents and technological advancement of Big Data

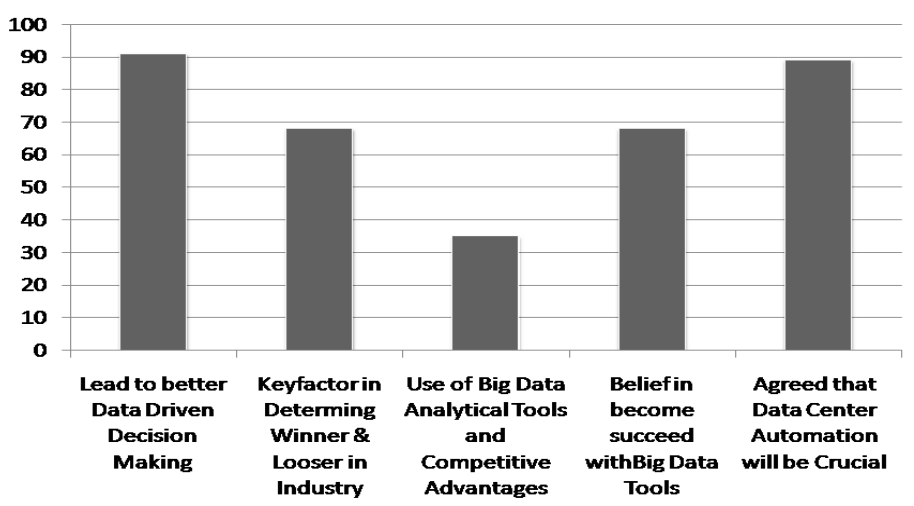

Fig.3 Impact Factor of Big Data Technological Advancement \& Percentage of Respondents

\section{Indian industries Diving Into Big Data Ocean}

Infosys Technologies Ltd [9] - It has started Big Data journey in early 2010 when the term Big Data was not even coined in India and they worked with some global companies in the industry to create their strategy around Big Data technologies to transform their IT and business at much lower cost at that point of time. Infosys grabbed the opportunity of Big Data \& launched a platform called 'BigDataEdge' in February 2013. It enables both real-time discoveries of data across internal systems, external sources and provides results by using rich visual interface with more than 50 customizable dashboards and 250 built-in algorithms. This platform also includes out-of-the-box applications for specific industry needs such as fraud detection and prevention, predictive analytics and monitoring, and customer micro-segmentation that deliver faster returns on investment. Infosys currently has over 50 engagements in the Big Data space across industry segments and the firm says that the number of engagements and projects are close to doubling every year

Wipro Technologies Ltd [10] - Wipro has developed a Big Data adoption framework, christened '3B framework', and has identified several system integration patterns for Big Data adoption to enable faster processing of data, reduction in development time and cost of processing. Wipro has also taken a more strategic approach by taking a minority position in Opera Solutions, LLC, and a leading global Big Data Science company. This strategic partnership will enable Wipro to create industry-specific Big Data analytics solutions like 720 degree customer analytics solution by combining Wipro's domain and technology expertise with Opera Solutions' machine learning expertise, pre-discovered predictive signals and algorithms. Wipro invest $\$ 30 \mathrm{M}$ in US-based Big Data firm Opera Solutions. It is founded in 2004, and also runs other offices in North America, Europe and Asia. It leverages advanced technology to extract value from Big Data and uses a combination of analytics technology, machine learning science, large-scale data management and human expertise to build and deliver analytics solutions.

HCL Technologies [11] - They are following a two-prong strategy for Big Data: Technology Up and Consulting Down and have Centers of Excellence as per different streams of Big Data \& help us to create the capability, capacity and proof of concept as per customer Big Data use cases

Happiest Minds Technologies [12] - It bullish on the opportunity in the Big Data space and ventured into Big Data less than two years ago, and has had a promising start by associating with key customers like large retailers and publishing houses.

Telecommunication - India's leading telecom operator Bharti Airtel Ltd. receives around 8 billion calls every day, amassing petabytes of data, while India's third-largest cellular services provider with 130 million subscribers, Reliance Communications, handles over 20 million calls every month from its customers. The challenge is to analyse the data to identify new opportunities and store them securely and affordably requires taking initiative with Big Data.

General Electric India[13],[15] - Based on its Big Data initiative, for instance, GE implemented a tool that monitors different parts of an aircraft during take-off, and then shares that information with the ground maintenance crew. GE is betting big on Big Data. According to GE's Industrial Internet report, it predicts that Big Data technology could result in a 5 percent cost reduction from better flight planning and operational changes. That's $\$ 8$ billion, about Rs 44,000 crore a year from a single business.

Philips India [14] executives hope that in the future Big Data could lead them to the Holy Grail of business: Competitive differentiation from new products. As the world's biggest lighting manufacturer, and 
Europe's largest consumer electronics producer, Philips generates tons of data. It's three highly-successful businesses - healthcare, lighting and consumer lifestyle - creates data in the range of several petabytes. They are using Big Data analytical tools as emerging technology to extract intelligence from larger datasets and these tools also help them to gain market share and profitability. Press reports of the company show that Philips is targeting sales growth in the range of 4-6 percent. Its business transformation and Big Data project could go a long way in helping it to reach the target even in a sluggish economy.

TVS Motor [17] Company's Big Data challenge is to find meaning in the surplus of unstructured data streaming in from its highly successful Social Media strategy, one that has ensured 150,000 likes and comments on TVS' Social Media page for big sellers like Scooty, Pep and Apache. And they plan to increase market share Social Medias.

NATGRID [18]-Government's ambitious counter terrorism programme, and will utilize technologies like Big Data and analytics to study and analyse the huge amounts of data from various intelligence and enforcement agencies to help track suspects and prevent such attacks. And Indian Government looking is at National Security and such technologies can track one's digital fingerprints, thereby making it easier for law enforcement agencies to track suspects and also analyse events to provide more insights to agencies, he added.

The real use for Big Data [15] comes in picture when corporate or consumers use it for business outcomes in decision-making or in operations management. As it stands today, Big Data demands the maturity of diverse technologies to deliver insights as well as an evolved consumer or corporate to handle big decisions out of it. And such entrepreneurs, organizations in India took initiatives to dive on the growing economical waves around the Big Data Ocean.

\subsection{To become prudent and getting prudency's with Software and Hardware Ecosystem}

Services \& Platforms - To become prudent with Big Data, upcoming new platforms and services are launched to become prudent with the Big Data. It offers way to make investment and provides support to run economy better with Big Data Market.

IBM [19] Big Data Platform helps clients discover big insights at the speed of business. IBM has the technology and the expertise to apply Big Data solutions in a way that addresses specific business problems and delivers rapid return on investment.

Cloudera [20] delivers the first enterprise-class implementation of Apache Hadoop \& help to deploy an Enterprise Data Hub to solve Data Management problems. In 2013, they released Solr Cloud on Hadoop which allows batch and streaming indexing.

HAVEn [21] - Aiming to expand its Big Data analytics portfolio, Hewlett-Packard has launched the Big Data analytics platform 'HAVEn', that leverages HP's analytics software, hardware and services to enable organizations to gain better insight into their data and deliver real-time outcomes and designed to work with next generation of Big Data-ready analytics applications and solutions.

Oracle's Big Data Solution [22] - Oracle is the first vendor to offer a complete and integrated solution to address the enterpriser's Big Data requirements. New Big Data technologies, such as Hadoop and Oracle NoSQL database run alongside with Oracle data warehouse to deliver business value.

\subsection{To become prudent and getting prudency's with Emerging Academic \& Acquisition of Job}

In India, the pool of talent availability is show in the following figure 4, and there is limited talent availability and low awareness about benefits of Big Data Analytics. The study report of annual potential talent pool describes that more number of IT Professionals are available as compared with others in India. Cloud computing, Big Data and analytics will be the hot areas and brings directly the revenue for the organisations. India will remain the preferred destination for analytics outsourcing compared with the Philippines and China. India itself will require a minimum of 1,00,000 data scientists in the next couple of years to gain the benefits of Big Data Analytical tools in driving the business. India's analytics talent pool will be in high demand because of their process expertise and have strength in recognizing the ecosystem problems.

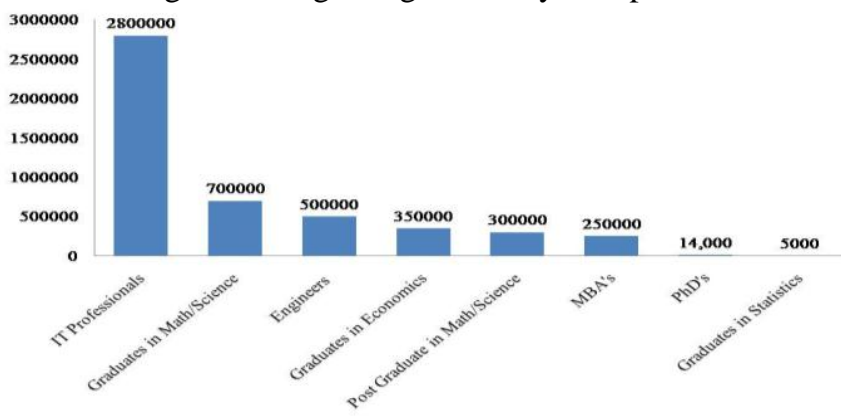

Figure 4 Annual Potential Talent Pool Available for Big Data in India. 
Hence to capture the Big Data market it is need to introduce Big Data into the curricula of graduate education system. In order to improve talent availability for Big Data, IT organisations like EMC, Oracle, IBM, Infosys, etc., are leveraging their academic alliance programmes, with universities in India and overseas to introduce courses in various areas related to the domain. Therefore, India is expected to emerge as a preferred destination for Big Data Analytics.

\subsection{Challenges}

According to IDC, NASSCOM, CRISL and TCS study report[23], there is big opportunity standing in front of Indian Economy to become prudent and big. Entrepreneurs are initiated to invest in Big Data but certain challenges are faced by them $\&$ these are:

- The finding and nourishing the talent and resources the business will need.

- Organizations have focused on hiring internal domain experts prepared with tools, resources and training. The company hired $30 \%$ of its workforce from outside who were trained in different analytical tools.

- Amount of preparation and ground work needed in terms of underlying transactional systems and the business processes that run on the systems to streamline the growth of business with respect to ROI before Big Data can take off.

- Understanding the Big Data Infrastructure and Third Party Service Providers is great challenge to manage large data sets with respect to Investment and ROI.

\subsection{The Future of Cloud Services in the Age of Big Data}

\section{Future Scope}

The use of Cloud Services in Big Data Technology may lead to run the business with low cost investment and it will be dependent on the budget, the type business and growth to decide whether to use Cloud Services or directly go for Big Data.

\subsection{The Future of Data Warehouses in the Age of Big Data}

Before the Big Data came into existence, the traditional data warehouse were designed to handle the structured data, and did not handle unstructured data generated from Social Media, Mobile Devices, Web traffic, etc. $90 \%$ of the data warehouses process just $20 \%$ of an enterprise's data \& enterprises have only been able to use their data warehouses for historical analysis, past performance reporting and are looking to make the use of expensive infrastructure to generate back office reports. Many companies are saddle with data warehouses that weren't designed to handle Big Data, but they can evolve their data warehouses into "analytics warehouses" capable of processing structured and unstructured data.

\section{Conclusion}

To become prudent and getting experience of it, it is essential to make determination about the plan of action, and need to implement it dedicatedly and devotionally to achieve the desired success on the track of will power. The A.P.J. Abdul Kalam says that," All Birds find shelter during a rain. But Eagle avoids rain by flying above the Clouds. Problems are common but attitude makes the difference" and the same situation is awaken in front of Industrialist, the pillars of Indian Economy about the Big Data Market. This paper proposed the study work about the current scenario of the Big Data Market in India, and how this opportunity is grabbed by the Industrialist? This paper also focuses on the challenges of Big Data in India.

\section{Acknowledgment}

We would like to thanks to Dr. Aniruddha D. Joshi, Dr. V. A. Raikar, Advisory Member, Prof. S. M. Ingale, In-charge Director, and Prof. A. S. Kamble H.O.D. of Computer Science \& Engineering Department, Sanjay Ghodawat Group of Institutions, Atigre for their valuable guidance and motivation for this work.

\section{REFERENCES}

[1] Gil Press, A very short history of Big Data, 2013, www.forbes.com

[2] Tekiner, Firat ; Keane, John A., Bramework, IEEE International Conf. on Systems, Man, and Cybernetics (SMC), 2013. Computer Science and Information Systems, Conference, 2013

[4] Jay Lee, Edzel Lapira, Behrad Bagheri, Hung-an Kao, Recent advances and trends in predictive manufacturing systems in big data environment,

ScienceDirect Journal, 1(1), October 2013

[5] IDC. Worldwide Big Data Technology and Services 2012-2015 Forecast. 〈http://www.idc.com.>

[6] NASSCOM \& CRISL, Big Data the next big thing report, <http: //www.nasscom.in.>

[7] Apache Hadoop, <http://hadoop.apache.org>

[8] Carl W. Olofson, Dan Vesset. Worldwide Hadoop - MapReduce Ecosystem Software 2012-2016 
[9] Infosys Technologies Ltd, <http: //www.infosys.com.>

[10] Wipro Technologies Ltd, 〈http: //www.wipro.com.>

[11] HCL Technologies, <http: //www.hcltech.com.>

[12] Happiest Minds Technologies, http://www.happiestminds.com/big-data-and-database-servcices

[13] General Electric India, http://www.ge-ip.com, http://www.ge.com

[14] Philips India , <http://www.philips.co.in >

[15] Shubhra Rishi, Big Data set to grow in the Indian Enterprise in 2013, Jan 28 2013. <http: //www.computerworld.in.>

[16] EMC, Create new business value with Big Data, <http://www.emc.com>

[17] TVS Motor, <http://www.tvsmotor.in.>

[18] NATGRID "To use of Big Data \& Analytics to track suspects", <http://articles.economictimes.indiatimes.com>

[19] IBM, Data growth and standards. http://www.ibm.com

[20] Cloudera Incorporated, <https://www.cloudera.com>

[21] HAVEN Platform, <http://www.hp.com/us/en/software-solutions/big-data-platform-haven.html>

[22] An Oracle White Paper: Big Data for the Enterprise, June 2013.

[23] A TCS Global Trend Study, The emerging big returns on Big Data, 2013 